Session 2354

\title{
The Engineer as Entrepreneur: Education for the 21st Century at Rose-Hulman Institute of Technology
}

\author{
Thomas W. Mason, Arthur B. Western \\ Rose-Hulman Institute of Technology
}

\begin{abstract}
Over the past five years, Rose-Hulman has invested over $\$ 40 \mathrm{M}$ dollars creating an environment to encourage entrepreneurship in its graduates. Components of the educational, organizational, and physical infrastructure are described. These components include a course in entrepreneurship, internships with entrepreneurial companies, the Technology and Entrepreneurship Development (TED) program, Rose-Hulman Ventures (RHV), and the John T. Myers Center for Technological Research with Industry. Case studies of recent successes are presented.
\end{abstract}

\section{Introduction - Educating the $21^{\text {st }}$ Century Engineer}

For almost two decades, Rose-Hulman has been searching for ways to prepare its graduates for the rapidly changing competitive environment facing those who contribute to advancing technology. The scale of this effort has been steadily increasing so that during the past five years over $\$ 40$ million has been invested in buildings, equipment, and people to implement this effort.

The fundamental problem addressed by all of the activities described below is the fact that engineers and scientists need more and broader knowledge to innovate successfully in the $21{ }^{\text {st }}$ Century. There is abundant evidence that producing the technically best product is no guarantee of commercial success, and the timing, cost, manufacturability, distribution and other factors related to an innovation may be more important than its functionality. This means that lots of disciplines must be brought to bear on design and implementation. Yet, engineering students must already absorb large volumes of technical information in crowded curricula, and the real need is for effective crossfunctional integration. Therefore, there is a need to give engineers awareness of these other aspects of the product and increase their ability to effectively communicate with the other professionals with whom they must work. Moreover, this must be done within a realistic context of speed and complexity. 
The various activities developed at Rose-Hulman are aimed at getting the engineer to think like an entrepreneur. That is, to encourage students to look for ways to use available resources in innovative and valuable ways. Fortunately, most of the characteristics needed to be entrepreneurial in $21^{\text {st }}$ Century technological organizations and marketplaces are also those identified for the well-prepared engineer. Both entrepreneur and engineer need intelligence, knowledge, courage, people skills, communication skills, and facility with uncertainty and risk. Rose-Hulman believes that it has found a number of ways to provide experiences in applying these traits within an undergraduate engineering education.

\section{Projects and Curricular Change at Rose-Hulman}

From the beginning, Rose-Hulman has recognized that realistic projects represent great vehicles for weaving the complex combination of forces affecting innovation directly into the learning process. In 1985 Rose-Hulman established, under the leadership of Dr. Brij Khorana, the Center for Applied Optics Studies (CAOS). The Center was the first formal industrial outreach program at Rose-Hulman. It was established to complement the then new Master's degree program in Applied Optics. The vision was to aid Indiana industry by supplying expertise in the enabling technology of optics while at the same time

providing M. S. students in Applied Optics with industry-based problems as thesis topics.

By the 1990s, several other departments shifted the format of senior capstone design projects to include external sponsors. The earliest adopters included Civil Engineering, Mechanical Engineering, and Computer Science. In 1993 Rose-Hulman created, with support from the Indiana Business Modernization and Technology Cooperation, the Technical Assistance and Services Center (TASC) as a vehicle through which additional industry-related projects could be made available to Rose-Hulman faculty and students. At about this time, Dr. Samuel F. Hulbert, president of Rose-Hulman, challenged the Institute faculty to provide at least one team-based project activity for every student before graduation.

In 1993 the Commission on the Future of Rose-Hulman Institute of Technology reinforced this vision. The Commission was comprised of 410 persons from across the nation and two foreign countries. Commission members included industrial executives, entrepreneurs, community leaders, scientists, military representatives, educators, financial authorities, physicians, attorneys, journalists, and government officials. The President's vision was echoed by the Commission's recommendation that "Rose-Hulman can strengthen its undergraduate offering by...[providing]... the opportunity for students to put their book skills to work solving real problems and making real products that work. The Commission believes that it is imperative to establish a coordinated and properly supported Rose-Hulman Undergraduate Design and Research (RUDR) program to (1) strengthen the design and research opportunities for undergraduates and (2) steer us to preeminence in this area." 
During the next seven years, the Institute was awarded a series of grants described in Sections IV through VI that has allowed it to come very close to the goal of $100 \%$ student participation in a team-based, industrially sponsored project, while at the same time creating an atmosphere that encourages innovation and entrepreneurship.

\section{The Entrepreneur Course}

While the project emphasis has clearly prepared graduates to more quickly adapt to the demands of the workplace, these projects often cannot contain sufficient business aspects to make them truly entrepreneurial experiences. In the 1980's, an undergraduate economics course called The Entrepreneur (VA453) was created to teach economic principles within the framework of developing innovations for the marketplace. It can be used by engineering students to meet part of their humanities and social science requirements, and it has been a popular elective, especially for technical students with some entrepreneurial interests. The objectives for the course are:

- Describe the role of the entrepreneur in society

- Describe the importance of entrepreneurial behavior in organizations of all sizes and types

- Identify traits and behaviors needed for successful entrepreneurship

- Use tools of economic analysis to analyze opportunities and efforts

- Apply the knowledge of the basic aspects of a business plan

- Communicate effectively in written and oral reports

- Describe sources of capital, talent and other resources for entrepreneurship

- Maintain a sense of fun and perspective about innovation and entrepreneurship

The objectives are achieved by studying relevant topics such as

- the framework of entrepreneurship,

- sustainable competitive advantages,

- analysis of opportunities

- the competitive environment

- the global nature of business

- and the construction of business plans

About $60 \%$ to $70 \%$ of class time is devoted to traditional lecture, class discussion and tests. Ten percent of the time is spent on discussions of case studies, which are basically critiques of business plans provided by the textbook, Marc Dollinger, Entrepreneurship: Strategies and Resources. ${ }^{1}$ Another ten percent of the classes are devoted to outside speakers; typically entrepreneurs at various levels of success, or relevant professionals like venture capitalists. A significant part of the course is devoted to the development and presentation of business plans by student teams. Tests (50\%), short papers (20\%), the business plan (20\%) and class participation (10\%) determine grades. 
The course has been quite successful in a number of respects. Enrollment has consistently been strong, and course evaluations indicate a high level of enthusiasm for the material and the approaches to it. Several alumni have commented that the course has been very helpful in starting technology-based businesses or in moving into management roles in existing ones. Two high tech companies have been started by students before graduation, and both of them are growing well. One has remained in Indiana and retained graduates of the school who otherwise would have left the state. While the course reaches only about 60 students per year and has little time to convey the complexities of business disciplines and business plan preparation, it has caused students to think about issues such as the importance of the customer's satisfaction and the need to integrate all of the requirements of successful commercialization of technology.

\section{The Entrepreneurial Internship Program}

The Entrepreneurial Internship (EI) program was established at Rose-Hulman to encourage small fast-growth companies to employ Rose-Hulman students for summer internships and co-op experiences. The intent is to encourage students to pursue an interest in working and contributing in such companies, and expose them to various business functions (marketing, sales, finance/budgeting/planning, customer service) not ordinarily part of most engineering internships. The EI program was established in 1995 through a grant from the Kauffman Foundation. In fact, Rose-Hulman was the first school to launch an entrepreneurial intern pilot program for Kauffman, and that foundation has extended it to a number of other institutions. In 1996, the Lilly Endowment, through the TED grant (described in Section V), provided funds for program expansion.

For purposes of the Entrepreneurial Internship program, an entrepreneurial company is defined as one with sales of less than $\$ 25 \mathrm{M} / \mathrm{yr}$ and fewer than 200 employees. For such companies accepting RHIT students as summer interns, Rose-Hulman pays $1 / 3$ of the students' wages which are required to be competitive (a minimum of $\$ 15 / \mathrm{hr}$ in summer 2000).

Students are selected by the Director of Career Services based upon results of an in-depth interview and a creative essay written by the applicant. Selected students are required to (1) read Innovation and Entrepreneurship ${ }^{2}$ by Peter Drucker and write a three-page paper summarizing the salient points; (2) Enroll in VA453, The Entrepreneur course described elsewhere in this article; (3) participate in wrap-up meetings to discuss participant experiences and outcomes of the program; (5) make a long-term commitment to find ways to support future Rose-Hulman engineering students interested in entrepreneurship.

As of May 2000, a total of 61 students had served in Entrepreneurial Internship programs and graduated from Rose-Hulman. Of this pool, 26 students took positions in small entrepreneurial businesses, 19 of them in Indiana. While the numbers are small the yield of $31 \%$ to small Indiana companies is encouraging. 
V. Technology and Entrepreneurial Development Program

In 1996 the Lilly Endowment, Inc. awarded a four-year, \$4 million grant to establish the Technology and Entrepreneurial Development (TED) Program. The goals of the program mirror those articulated by the Rose-Hulman Commission on the Future: (1) increase industry-related project opportunities for students and faculty; (2) develop product and process development laboratories; (3) establish entrepreneurial internships for students; (4) encourage interdisciplinary teams of faculty and students to work on projects that have the potential for commercialization of a new product or process.

As indicated in Table I, during the four years of the TED project the number of student and industry participants has increased to a sustainable plateau of approximately one half of the Rose-Hulman student body participating in any one year. A survey of faculty during the 1999-2000 Academic year indicated that 52\% of RHIT faculty members have supervised one or more projects.

Table I. Student Participation in Project Work

\begin{tabular}{|l|c|c|}
\hline Year & Student x quarters (total students) & Number of Projects with External Sponsors \\
\hline $1996-97$ & $940(483)$ & 134 \\
\hline $1997-98$ & $1266(310)$ & 86 \\
\hline $1998-99$ & $2199(850)$ & 279 \\
\hline $1999-00$ & $1876(817)$ & 235 \\
\hline
\end{tabular}

To reiterate, our goal is that "Every Rose-Hulman student have the opportunity to experience the excitement of the experimentation and discovery process prior to graduation." As Table II shows $99 \%$ of the students receive at least one such experience and $76 \%$ of these are for an external clients.

TABLE II. Summary of Upper Division Research and Design Courses

\begin{tabular}{|l|c|c|c|c|}
\hline Departments & Majors/total & Credits & Required & External Clients \\
\hline Chemical Engineering & $17 \%$ & 8 & yes & no \\
\hline Chemistry & $3 \%$ & 2 & yes & no \\
\hline Civil Engineering & $8 \%$ & 6 & yes & yes \\
\hline Computer Science & $10 \%$ & 8 & yes & yes \\
\hline Electrical and C Eng. & $26 \%$ & 10 & yes & yes \\
\hline Mathematics & $1 \%$ & var & no & no \\
\hline Mechanical Eng. & $32 \%$ & 4 & yes & yes \\
\hline Physics \& A.O. & $3 \%$ & 4 & yes & no \\
\hline
\end{tabular}

VI. The Center for Technological Research with Industry

Department of Energy awarded to Rose-Hulman a \$6.7 million grant to construct the 40,000 square foot John T. Meyers Center for Technological Research with Industry

Proceedings of the 2001 American Society for Engineering Education Annual Conference \& Exposition Copyright (C) 2001, American Society for Engineering Education 
(CTRI). The building's flexible work space allows interdisciplinary teams of students and faculty to design and construct projects, moving from space to space through various phases of the product and process development.

The Myers Center is unique amongst campus buildings in that, by faculty mandate, individual academic departments are not permitted to lay claim to space within the building. Project spaces are assigned upon request for the fixed duration of the project only. After project completion, the spaces are vacated and reassigned. Current space assignments range from commercial projects being carried out under the direction of entrepreneurs-in-residence to academic-based capstone design projects being done for external sponsors.

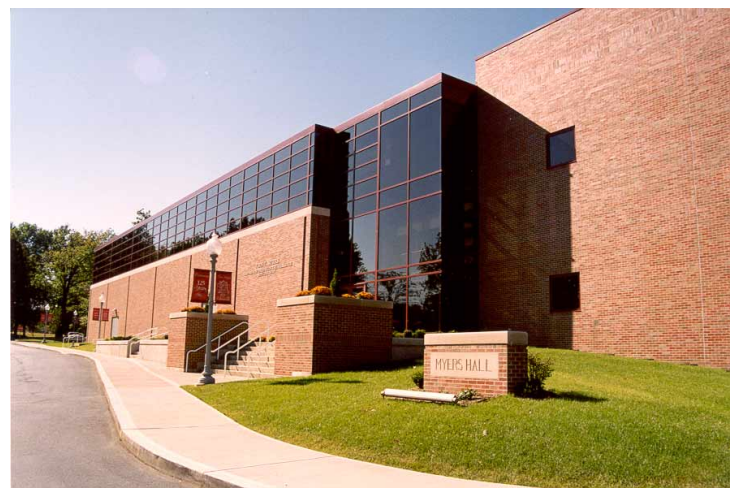

Figure 1. The John T. Myers Center for Technological Research with Industry

In addition, the Myers Center houses a number of specialty support labs that serve a variety of projects. These labs include rapid prototyping, printed circuit board fabrication, an electrical calibration laboratory, material testing laboratory, and chemical analysis laboratory. The rapid prototyping center includes, in addition to 3-D modeling software, two 3-D printing systems: a Z402 for starch-based models and a StrataSys 3000 system for ABS plastic and wax prototypes. A laser sintering system is available at the Aleph Park campus of Rose-Hulman Ventures. The rapid prototyping center also houses a desktop CNC milling machine and lathe. The printed circuit board facility provides computer-controlled milling of circuit boards up to six layers, with robotic surface mount and soldering oven capabilities. The materials testing facilities include a low-pressure scanning electron microscope and MTS fatigue test apparatus.

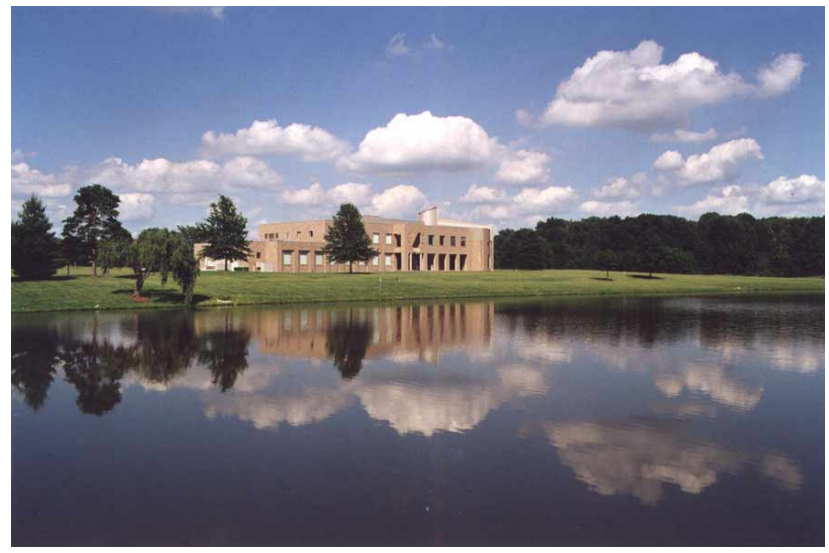

Figure 2. South Hall at the RoseHulman Aleph Park campus is the home of Rose-Hulman Ventures.

Proceedings of the 2001 American Society for Engineering Education Annual Conference \& Exposition Copyright (C) 2001, American Society for Engineering Education 
In the year 2000, an additional $\$ 29.7 \mathrm{M}$ grant from Lilly Endowment created RoseHulman Ventures (RHV). The creation of RHV moved these efforts to a new level that includes business incubator space and venture capital. We anticipate reporting on the activities of RHV in a future paper.

\section{Case Studies}

Particular examples help illustrate the synergy of the components of the entrepreneurial infrastructure. Rose-Hulman undergraduate Dustin Sapp worked at Logikos in the summer of 1999 as an Entrepreneurial Intern sponsored by the TED program. Another student Aaron Nelson took a course in Entrepreneurship at Rose-Hulman. In the 19992000 academic year, the two teamed up to take an independent study course under direction of Dr. Tom Mason. With additional support from the Kauffman Foundation, the students were assigned project space in the Myers Center and developed applications for the increasingly popular personal digital assistant technology. By the end of the year, they formed a company, NoInk, with fellow student Robert Harris and became the first resident tenants at the new Rose-Hulman Ventures incubator at Aleph Park and employed entrepreneurial interns themselves.

In a second example, student Jim Hicks took a course in computer-aided manufacturing from Prof. Rick Stamper. In the course Prof. Stamper introduced the new StrataSys rapid prototyping machine recently installed in the Myers Center. Jim was aware of a problem in his father's business: the wear pieces on the blades of the ceramic mixing machine, which have to be replaced regularly, were currently made by an expensive custom machining process. Jim's idea was to replace the machining process by much less expensive cast parts by using CAD/CAM to produce investment cast patterns. Material costs for proof of concept designs were provided through TED funds. After initial success, the higher volume rapid prototyping facilities at Rose-Hulman Ventures were used to generate the wax models from which casting patterns were created. The company assumed the costs for final production. End result: the company is saving over 50\% on the costs of wear blade replacements. More important for Rose-Hulman's objectives is that this highly visible project demonstrated the value of innovation to all of the students and faculty who were aware of it. Regarding the experience, in the student's words, "...looking back on it, I feel that it probably taught me more about engineering than any other class that I have taken so far."

\section{Conclusions}

Rose-Hulman is convinced that students must be prepared to thrive in entrepreneurial cultures and that creating such a culture on the college campus requires a multi-prong approach. It is necessary for campus leadership, including the president and the board, to espouse the desirability of fostering innovation and its commercial application. After that, individual departments can contribute in different ways, from courses in entrepreneurship to industry-sponsored projects. In all this, the investment in infrastructure, equipment and project space, can be considerable. However, change in 
education, like change in technology, requires the willingness to commit resources in anticipation of future benefits. The early returns for Rose-Hulman and our students have already shown that these investments have been good ones.

\section{Acknowledgements}

The authors gratefully acknowledge support for entrepreneurship programs at RoseHulman from the Lilly Endowment, Inc. through grants 960068 and 1999-1525-000, and from the Ewing Marion Kauffman Foundation.

Bibliography

1. Dollinger, Marc, Entrepreneurship: Strategies and Resources. Upper Saddle River, NJ: Prentice Hall, (1999).

2. Drucker, Peter F., Innovation and Entrepreneurship: Practice and Principles. New York, NY:

Harperbusiness (1993).

THOMAS W. MASON

Thomas W. Mason is currently Vice President for Entrepreneurship \& Business Planning of Rose-Hulman Ventures at Rose-Hulman Institute of Technology in Terre Haute, Indiana. He is also director of the Institute's Master of Science in Engineering Management program, and his experience includes being CFO and CEO of a computer systems business. Dr. Mason received his BA in economics from Geneva College and earned an M. A. and Ph. D. in economics at the University of Pittsburgh.

ARTHUR B. WESTERN

Art Western is Professor of Physics \& Applied Optics and Associate Dean of the Faculty at Rose-Hulman Institute of Technology. He oversees the John T. Myers Center for Technological Research with Industry and, for a year and a half, served as director of the Technology and Entrepreneurial Development (TED) program. Dr. Western received the B. S. degree from Rollins College, Winter Park, Florida and the Ph. D. in physics from Montana State University.

Proceedings of the 2001 American Society for Engineering Education Annual Conference \& Exposition Copyright (C) 2001, American Society for Engineering Education 